\title{
Genetic characteristics of non-Hodgkin lymphoma in ethnic Uighur people, and their clinical significance
}

\author{
L. Xu' ${ }^{1}$, X.G. Zou' ${ }^{1}$ X. Wang', A.B.L.M.T. Hairesa ${ }^{1}$ and J.J. Liu ${ }^{2}$ \\ ${ }^{1}$ Department of Hematology, \\ First People's Hospital in Kashgar (Kashi) Prefecture, Xinjiang, China \\ ${ }^{2}$ Department of Hematology, \\ The Third Affiliated Hospital of Sun Yat-sen University, Guangdong, China \\ Corresponding author: J.J. Liu \\ E-mail: lixuvbn@sina.com
}

Genet. Mol. Res. 15 (4): gmr15048960

Received July 12, 2016

Accepted October 19, 2016

Published December 2, 2016

DOI http://dx.doi.org/10.4238/gmr15048960

Copyright $(2016$ The Authors. This is an open-access article distributed under the terms of the Creative Commons Attribution ShareAlike (CC BY-SA) 4.0 License.

\begin{abstract}
The incidence of non-Hodgkin lymphoma (NHL) in China is increasing and is attracting attention as a topic of research. The percentage of NHL cases in ethnic Uighur people is also gradually increasing. We therefore recruited Uighur people with NHL to investigate the correlation between genetic alternations and clinical/pathological features in an attempt to determine their clinical significance. A total of $60 \mathrm{NHL}$ patients were recruited from our hospital for a microscopic examination of their tumor cell morphology. Further analysis of chromosome karyotypes revealed the relationship between genetic alternations and clinical/pathological features. Microscopic examination revealed increased numbers of tumor cells with altered morphology. The recruited patients all exhibited abnormal karyotypes. Chromosomal breakages were detected at 14q32, 18q21, 6q21-25, +3,
\end{abstract}


,++18 , and short tandem repeat 17 (str17) in 18.3, 25, 25, 18.3, 15, and $21.7 \%$ of patients, respectively. Karyotype change was not related to age, gender, performance status score, or pathological type $(\mathrm{P}>0.05)$, but was correlated with clinical stage, average lactate dehydrogenase (LDH) level, extra-lymphatic metastasis, median survival time, and efficacy of radio- or chemotherapy $(\mathrm{P}<0.05)$. Independent risk factors for genetic change in Uighur NHL patients included clinical stage, average LDH level, extra-lymphatic metastasis, median survival time, and efficacy of radio- or chemotherapy $(\mathrm{P}<0.05)$. Uighur NHL patients exhibited genetic changes including $\mathrm{t}(14: 18), 6 \mathrm{q} 21-25,+3,+7,+18$, and str17. Clinical stage, average LDH level, extra-lymphatic metastasis, median survival time, and efficacy of radio- or chemotherapy were all independent risk factors for NHL.

Key words: Uighur ethnic group; Non-Hodgkin lymphoma; Chromosome mutation

\section{INTRODUCTION}

Malignant lymphoma is a common tumor in humans. Its incidence is increasing significantly worldwide, and it accounts for $3-4 \%$ of all malignant tumors. The incidence of and mortality from lymphoma are higher in the Uighur ethnic group of Xinjiang than in people from eastern coastal regions. With a male to female ratio of 2.3:1, lymphoma has two peaks of incidence at younger than 10 years and 31-50 years in the population (Pervez et al., 2009). Malignant lymphoma has highly homogenous features but has various subtypes and classifications. To improve diagnosis and treatment efficacy, the clinical and pathological classification criteria for lymphoma are continuously updated with precise guidelines (Stewart et al., 2009). Non-Hodgkin lymphoma comprises a group of heterogeneous diseases with different etiologies and biological features (Rossi et al., 2009). Based on the hematological tumor and lymphoma classification system stipulated by the World Health Organization (WHO), a confirmed diagnosis of malignant lymphoma requires descriptions of the morphology, immune phenotype, genetics, and clinical features (Smedby et al., 2006). Owing to its migration and heterogeneous characteristics, the major clinical manifestations and biological features of NHL are difficult to describe precisely under the current pathological classification system. Therefore, its clinical diagnosis and treatment are compromised (Wang et al., 2013). Recently, the examination of chromosome karyotypes has attracted a great deal of attention from researchers. The investigation of chromosome change in malignant tumors for purposes of prognosis has achieved certain outputs. Previous studies on malignant hematological tumors have established the chromosome assay as an important and independent technique for guiding a patient's prognosis (Yoon et al., 2008). Another study on NHL showed that certain featured chromosome translocations may be valuable for patient prognosis prediction and for improving diagnosis accuracy and treatment compared with histology classification, which may have significant implications for clinical work (Basso et al., 2010). Therefore, in this study, we recruited Uighur NHL patients from our hospital to investigate the correlation between genetic change and clinical efficacy, prognosis, and the subtypes of Uighur NHL patients to provide evidence for treatment plan selection and overall evaluation.

Genetics and Molecular Research 15 (4): gmr15048960 


\section{MATERIAL AND METHODS}

\section{General information}

We recruited 60 Uighur NHL patients from the First People's Hospital in Kashi Prefecture between January 2015 and January 2016. The patients were evaluated according to history of primary diagnosis, body examination, imaging, and bone marrow biopsy. All recruited patients were primary patients who received pathological examination of the lymph nodes or extra-node tumors, plus bone marrow smear slide and chromosome examination. The diagnosis and staging of NHL followed the hematology guidelines for diagnosis and treatment efficacy. The Ann Arbor system was used for the staging of intra-node NHL patients, and the Lugano system was used for patients with NHL derived from gastrointestinal or other extranode sites. The NHL patients comprised 22, 18, and 20 cases of B cell, T cell, and NK/T cell origin, respectively. There were 30 males and 30 females in the patient group, with an average age of $50.2 \pm 3.5$ years (20-80 years). Clinical staging assessment revealed 5, 25, 19 , and 11 cases with stage I, stage II, stage III, and stage IV NHL, respectively. The treatment plan and focal radiotherapy were employed using the CHOP plan [CHOP is named after the initials of the drugs used, namely: cyclophosphamide, doxorubicin (hydroxydaunomycin), vincristine $\left(\right.$ Oncovin $\left.^{\circledR}\right)$, and prednisolone (a steroid)]. The evaluation of treatment efficacy and survival period followed the WHO guidelines. There were 19, 15, 16, and 10 cases of complete remission, partial remission, stable disease, and progressed disease, respectively.

This study was pre-approved by the Ethical Committee of the First People's Hospital in Kashi Prefecture. All subjects signed consent forms before recruitment to the study.

\section{Reagents and instruments}

We used a CytoVision ${ }^{\mathrm{TM}}$ chromosome imaging system produced by Applied Imaging (Rochester, NY, USA). Reagents for hematoxylin and eosin stain, and Giemsa stain were bought from Beisuo Biotech (Zhuhai, Guangdong, China).

\section{Chromosome analysis}

Samples were collected from all NHL patients to prepare chromosome and R bands. Cell suspensions were prepared and placed in a $37^{\circ} \mathrm{C}$ incubator for $24 \mathrm{~h}$, vortexing twice in the morning and evening. NSC-3096 was added to arrest the cells at the metaphase of mitosis. The incubation was stopped after $1 \mathrm{~h}$, with a final concentration at $0.05 \mathrm{mg} / \mathrm{mL}$. The mixture was then centrifuged at $1000 \mathrm{~g}$ for $10 \mathrm{~min}$. The supernatant was removed, $6 \mathrm{~mL} \mathrm{KCl}$ buffer $(0.075 \mathrm{M})$ was added, and the cells were incubated at $37^{\circ} \mathrm{C}$ for $30 \mathrm{~min}$. Iced methanol-acetic acid solution (3:1) was added to fix the cells, which were then centrifuged at $132 \mathrm{~g}$ for $10 \mathrm{~min}$ in triplicate. A disposable dropper was used to apply the cell suspension to glass slides ( 2 drops each), followed by drying, addition of Earle's solution, and heating in a warm bath $\left(87.5^{\circ} \mathrm{C}\right)$ for 60 min. Freshly prepared $10 \%$ Giemsa stain was used for 10 min.

The judgement criteria were as follows. A total of 20 mitotic phases were analyzed in individuals with normal karyotypes, whereas 10 phases were analyzed in patients with abnormal karyotypes. Those individuals with two or more identical karyotype abnormalities were identified as abnormal clones.

Genetics and Molecular Research 15 (4): gmr15048960 


\section{Data processing}

The SPSS 17.0 software was used for data analysis. The enumeration data were investigated using the chi-square test, whereas the measurement data were investigated using analysis of variance (ANOVA); both sets of data are reported as means \pm standard deviation. A logistic regression model was used for multivariate analysis. Statistical significance was defined as $\mathrm{P}<0.05$.

\section{RESULTS}

\section{Morphology of Uighur NHL patients viewed under a microscope}

The tumor cells showed diffused and infiltrative growth, with a partial increase of volume and oval or round nuclei. Two or three nucleoli were observed adjacent to the nuclear membrane, which exhibited thickening (Figure 1).

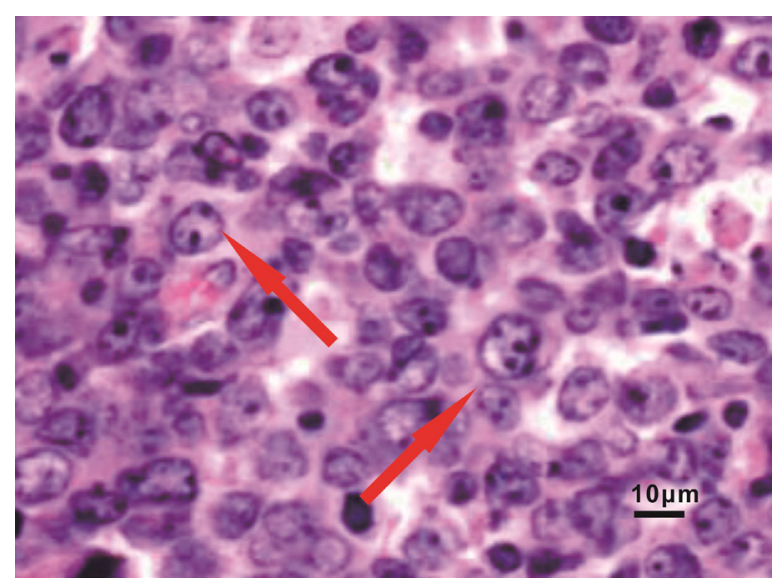

Figure 1. Cell morphology of Uighur NHL patients (200X).

\section{Genetic alternation in Uighur NHL patients}

The chromosome karyotype was examined in all the recruited Uighur NHL patients. The results showed abnormal karyotypes in the patients. There were 11 cases (18.3\%) of chromosome breakage at $14 \mathrm{q} 32$ or $18 \mathrm{q} 21,15$ cases $(25 \%)$ at $6 \mathrm{q} 21-25,15$ cases $(25 \%)$ at $+3,11$ cases $(18.3 \%)$ at $+7,9$ cases $(15 \%)$ at +18 , and 13 cases $(21.7 \%)$ at short tandem repeat 17 (str17).

\section{Correlation between genetic change and clinical/pathological features of Uighur NHL patients}

Correlation analysis was carried out between genetic change in NHL patients and clinical/pathological features including age, gender, performance status (PS) score, pathological type, clinical stage, average lactate dehydrogenase (LDH) level, extra-node metastasis, median survival period, efficacy of radio- and chemotherapy, and efficacy evaluation. The

Genetics and Molecular Research 15 (4): gmr15048960 
results showed no correlation between genetic changes such as t(14:18), 6q21-25, $+3,+7,+18$, and str17 and age, gender, PS score, or pathological type $(\mathrm{P}>0.05)$. However, these genetic changes were correlated with clinical stage, average LDH level, extra-node metastasis, median survival period, radio- or chemotherapy efficacy, and efficacy evaluation $(\mathrm{P}<0.05$, Table 1$)$.

\begin{tabular}{|c|c|c|c|c|c|c|c|}
\hline Item & $\mathrm{N}$ & $\mathrm{t}(14 ; 18)$ & $6 \mathrm{q} 21-25$ & +3 & +7 & +18 & str17 \\
\hline \multicolumn{8}{|l|}{ Age } \\
\hline$<45$ & 29 & $5(17.2)$ & $7(24.1)$ & $7(24.1)$ & $5(17.2)$ & $4(13.8)$ & $6(20.7)$ \\
\hline$\geq 45$ & 31 & $6(19.3)$ & $8(25.8)$ & $8(25.8)$ & $6(19.3)$ & $5(16.1)$ & $7(22.1)$ \\
\hline$P$ value & & $>0.05$ & $>0.05$ & $>0.05$ & $>0.05$ & $>0.05$ & $>0.05$ \\
\hline \multicolumn{8}{|l|}{ Gender } \\
\hline Male & 30 & $6(20)$ & $8(26.7)$ & $7(23.3)$ & $5(16.7)$ & $5(16.7)$ & $7(23.3)$ \\
\hline Female & 30 & $5(16.7)$ & $7(23.3)$ & $8(26.7)$ & $6(20)$ & $4(13.3)$ & $6(20)$ \\
\hline$P$ value & & $>0.05$ & $>0.05$ & $>0.05$ & $>0.05$ & $>0.05$ & $>0.05$ \\
\hline \multicolumn{8}{|l|}{ PS } \\
\hline$\leq 1$ & 28 & $5(17.8)$ & $7(25)$ & $8(25)$ & $5(17.8)$ & $4(14.3)$ & $6(21.4)$ \\
\hline$>2$ & 32 & $6(18.7)$ & $8(25)$ & $7(25)$ & $6(18.7)$ & $5(15.6)$ & $7(21.8)$ \\
\hline P value & & $>0.05$ & $>0.05$ & $>0.05$ & $>0.05$ & $>0.05$ & $>0.05$ \\
\hline \multicolumn{8}{|c|}{ Pathology } \\
\hline $\mathrm{T}$ cell & 22 & $4(18.2)$ & $6(27.3)$ & $5(22.7)$ & $4(18.2)$ & $3(13.6)$ & $5(22.7)$ \\
\hline B cell & 18 & $3(16.7)$ & $4(22.2)$ & $5(27.8)$ & $3(16.7)$ & $3(16.7)$ & $4(22.2)$ \\
\hline $\mathrm{NK} / \mathrm{T}$ & 20 & $4(20)$ & $5(25)$ & $5(25)$ & $4(20)$ & $3(15)$ & $4(20)$ \\
\hline P value & & $>0.05$ & $>0.05$ & $>0.05$ & $>0.05$ & $>0.05$ & $>0.05$ \\
\hline \multicolumn{8}{|c|}{ Clinical stage } \\
\hline I & 6 & $1(16.7)$ & $1(16.7)$ & $1(16.7)$ & $1(16.7)$ & $0(16.7)$ & $0(16.7)$ \\
\hline II & 24 & $4(16.7)$ & $4(16.7)$ & $3(12.5)$ & $3(12.5)$ & $3(12.5)$ & $3(12.5)$ \\
\hline III & 19 & $3(15.8)$ & $5(26.3)$ & $6(31.5)$ & $3(15.8)$ & $3(15.8)$ & $5(26.3)$ \\
\hline IV & 11 & $3(27.2)$ & $5(45.5)$ & $5(45.5)$ & $4(36.4)$ & $3(27.2)$ & $5(45.5)$ \\
\hline P value & & $<0.05$ & $<0.05$ & $<0.05$ & $<0.05$ & $<0.05$ & $<0.05$ \\
\hline \multicolumn{8}{|c|}{ Average LDH } \\
\hline$\leq 225 \mathrm{U}$ & 25 & $3(12)$ & $4(16)$ & $5(20)$ & $4(16)$ & $2(8)$ & $3(12)$ \\
\hline$>225 \mathrm{U}$ & 35 & $8(22.9)$ & $11(31.4)$ & $10(28.6)$ & $7(20)$ & $7(20)$ & $10(28.6)$ \\
\hline $\mathrm{P}$ value & & $<0.05$ & $<0.05$ & $<0.05$ & $<0.05$ & $<0.05$ & $<0.05$ \\
\hline \multicolumn{8}{|c|}{ Metastasis } \\
\hline Single & 28 & $3(10.7)$ & $4(14.3)$ & $5(17.9)$ & $4(14.3)$ & $2(7.1)$ & $3(10.7)$ \\
\hline Multiple & 32 & $8(25)$ & $11(34.3)$ & $10(31.3)$ & $7(21.9)$ & $7(21.9)$ & $10(31.3)$ \\
\hline P value & & $<0.05$ & $<0.05$ & $<0.05$ & $<0.05$ & $<0.05$ & $<0.05$ \\
\hline \multicolumn{8}{|c|}{ Median survival time (months) } \\
\hline$>12$ & 27 & $4(14.8)$ & $4(14.8)$ & $4(14.8)$ & $3(11.1)$ & $3(11.1)$ & $4(14.8)$ \\
\hline$\leq 12$ & 33 & $7(21.2)$ & $11(33.3)$ & $11(33.3)$ & $8(90.9)$ & $6(18.2)$ & $9(27.3)$ \\
\hline P value & & $<0.05$ & $<0.05$ & $<0.05$ & $<0.05$ & $<0.05$ & $<0.05$ \\
\hline \multicolumn{8}{|c|}{ Radiotherapy } \\
\hline No & 26 & $3(11.5)$ & $4(15.4)$ & $3(11.5)$ & $4(15.4)$ & $2(7.7)$ & $3(11.5)$ \\
\hline Yes & 34 & $8(23.5)$ & $11(32.4)$ & $12(35.3)$ & $7(20.6)$ & $7(20.6)$ & $10(29.4)$ \\
\hline P value & & $<0.05$ & $<0.05$ & $<0.05$ & $<0.05$ & $<0.05$ & $<0.05$ \\
\hline \multicolumn{8}{|c|}{ Chemotherapy } \\
\hline No & 31 & $4(93.5)$ & $5(16.1)$ & $4(12.9)$ & $3(9.7)$ & $2(6.5)$ & $4(12.9)$ \\
\hline Yes & 29 & $7(24.1)$ & $10(34.5)$ & $11(37.9)$ & $8(27.6)$ & $7(24.1)$ & $9(31)$ \\
\hline$P$ value & & $<0.05$ & $<0.05$ & $<0.05$ & $<0.05$ & $<0.05$ & $<0.05$ \\
\hline \multicolumn{8}{|l|}{ Efficacy } \\
\hline $\mathrm{CR}$ & 19 & $0(0)$ & $1(16.7)$ & $1(16.7)$ & $1(16.7)$ & $0(16.7)$ & $0(16.7)$ \\
\hline PR & 15 & $3(20)$ & $3(20)$ & $3(20)$ & $2(13.3)$ & $2(13.3)$ & $3(20)$ \\
\hline SD & 16 & $4(25)$ & $5(31.3)$ & $6(37.5)$ & $4(25)$ & $4(25)$ & $5(31.3)$ \\
\hline PD & 10 & $4(40)$ & $6(60)$ & $5(50)$ & $4(40)$ & $3(30)$ & $6(60)$ \\
\hline$P$ value & & $<0.05$ & $<0.05$ & $<0.05$ & $<0.05$ & $<0.05$ & $<0.05$ \\
\hline
\end{tabular}

\section{Multivariate analysis of correlation between genetic change in Uighur NHL patients and clinical/pathological features}

We carried out multivariate analysis on the correlation between genetic change in the 
Uighur NHL patients and clinical/pathological features. The results revealed that clinical stage, average LDH level, extra-node metastasis, median survival period, radio- and chemotherapy efficacy, and efficacy evaluation were independent risk factors for genetic alternation in the Uighur NHL patients $(\mathrm{P}<0.05$, Table 2$)$.

Table2. Multi-variant analysis between genetic change of UighurNHL patients and clinical/pathological features.

\begin{tabular}{|c|c|c|c|c|c|c|c|}
\hline & $\begin{array}{c}\text { Clinical } \\
\text { stage }\end{array}$ & $\begin{array}{l}\text { Average } \\
\text { LDH }\end{array}$ & $\begin{array}{c}\text { Extra-node } \\
\text { metastasis }\end{array}$ & $\begin{array}{l}\text { Median survival time } \\
\text { (months) }\end{array}$ & Radiotherapy & Chemotherapy & $\begin{array}{c}\text { Efficacy } \\
\text { evaluation }\end{array}$ \\
\hline \multicolumn{8}{|l|}{$t(14 ; 18)$} \\
\hline Regression coefficient & 0.724 & 0.613 & 0.801 & 0.697 & 0.733 & 0.821 & 0.992 \\
\hline$P$ & 0.003 & 0.002 & 0.004 & 0.003 & 0.003 & 0.002 & 0.001 \\
\hline Relative risk & 2.125 & 2.003 & 2.228 & 2.015 & 2.142 & 2.068 & 2.272 \\
\hline \multicolumn{8}{|l|}{$6 \mathrm{q} 21-25$} \\
\hline Regression coefficient & 1.132 & 1.124 & 1.275 & 1.233 & 1.214 & 1.083 & 1.171 \\
\hline $\mathrm{P}$ & 0.002 & 0.001 & 0.001 & 0.002 & 0.001 & 0.002 & 0.002 \\
\hline Relative risk & 2.027 & 2.015 & 2.852 & 2.325 & 2.453 & 2.501 & 2.244 \\
\hline \multicolumn{8}{|l|}{+3} \\
\hline Regression coefficient & 1.007 & 1.014 & 1.018 & 1.124 & 1.024 & 0.869 & 1.426 \\
\hline $\bar{P}$ & 0.001 & 0.002 & 0.001 & 0.002 & 0.001 & 0.002 & 0.004 \\
\hline Relative risk & 2.004 & 2.027 & 2.812 & 2.623 & 2.087 & 2.683 & 2.022 \\
\hline \multicolumn{8}{|l|}{+7} \\
\hline Regression coefficient & 1.113 & 1.213 & 1.004 & 1.015 & 1.044 & 1.075 & 1.403 \\
\hline $\mathrm{P}$ & 0.002 & 0.004 & 0.001 & 0.001 & 0.002 & 0.001 & 0.003 \\
\hline Relative risk & 2.892 & 2.367 & 2.730 & 2.457 & 2.716 & 2.452 & 2.028 \\
\hline \multicolumn{8}{|l|}{+18} \\
\hline Regression coefficient & 0.748 & 0.892 & 0.952 & 0.878 & 1.116 & 0.813 & 0.91 \\
\hline $\mathrm{P}$ & 0.002 & 0.003 & 0.003 & 0.002 & 0.002 & 0.002 & 0.003 \\
\hline Relative risk & 2.156 & 2.368 & 2.376 & 2.054 & 2.211 & 2.103 & 2.208 \\
\hline \multicolumn{8}{|l|}{ Str17 } \\
\hline Regression coefficient & 1.005 & 1.017 & 1.008 & 1.104 & 1.153 & 1.162 & 1.203 \\
\hline $\mathrm{P}$ & 0.001 & 0.002 & 0.002 & 0.001 & 0.002 & 0.003 & 0.001 \\
\hline Relative risk & 2.247 & 2.127 & 2.502 & 2.273 & 2.034 & 2.214 & 2.104 \\
\hline
\end{tabular}

\section{DISCUSSION}

The WHO has stipulated a classification system for malignant hematological and lymphatic tumors, for which differential diagnoses should be made from morphology, immune phenotype, genetics, and clinical features (Ferlay et al., 2010; Roman and Smith, 2011; Siegel et al., 2014). Currently, the epidemiology and geographical distribution of NHL varies across countries. In Uighur regions of China, the incidence of NHL of different subtypes is relatively high and is similar to that found in Japan or Korea, but differs greatly from Western countries (Luminari et al., 2007; Kim et al., 2011). Therefore, the stipulation of individualized treatment strategies based on prognostic parameters is critical for improving treatment efficacy and patient survival.

For this study, we recruited NHL patients from the Uighur people of China. Microscopic observation revealed diffused infiltrative growth with partially dilated volume and oval/round shape. Two or three nucleoli were visible adjacent to the nuclear membrane, which was thickened. Chromosome karyotype investigation revealed abnormal karyotypes, with $18.3 \%$ of chromosome breakage at $14 \mathrm{q} 32$ or $18 \mathrm{q} 21,25 \%$ at $6 \mathrm{q} 21-25,25 \%$ at $+3,18.3 \%$ at $+7,15 \%$ at +18 , and $21.7 \%$ at $\operatorname{str} 17$.

This study revealed genetic changes in Uighur NHL patients including $\mathrm{t}(14: 18), 6 \mathrm{q} 21-$ $25,+3,+7,+18$, and str 17 . Such genetic alternations were correlated with clinical stage, average LDH level, extra-node metastasis, median survival period, radio- and chemotherapy efficacy, and efficacy evaluation, but not with age, gender, PS score, or pathology type. For those patients 
at an advanced clinical stage, it is easier to demonstrate correlation between genetic change and elevated LDH level, occurrence of extra-node metastasis, shortened median survival period, efficacy of radio- or chemotherapy, or unfavorable treatment efficacy. Histological examination is important for predicting survival period and evaluating treatment efficacy, and is correlated with patient prognosis. However, the change of chromosome karyotype is an important independent risk factor for NHL prognosis in addition to its histological implications (Chen et al., 2013). One study has shown multiple critical chromosome karyotype changes in NHL patients, and their significant effect on patient treatment efficacy and median survival period (Zhang et al., 2013). Certain complex changes in chromosome karyotype or rearrangement, and some special chromosome genesis abnormalities such as $\mathrm{t}(8: 14)(\mathrm{q} 24: \mathrm{q} 32)$ translocation and +7, are unfavorable prognostic factors for NHL (Kahl and Yang, 2008; Zhang et al., 2010. Certain basic studies have shown no dysfunction of known genes located in the 6q21-25 region in NHL patients. In lymphocyte leukemia, however, certain gene dysfunctions occur in known genes in the 6q21-25 region (Klein et al., 2003; Streubel et al., 2003). Previous studies have shown that (t14:18), chromosome 7 abnormalities, and polyploidy chromosomes have the most significant effects on NHL patient survival periods (Kyle and Rajkumar, 2006). It has been reported that NHL patients with chromosome 7 abnormalities have unfavorable prognoses, chemo-resistance, and relatively higher mortality (Isaacson and Du, 2004). Moreover, NHL patients with abnormal chromosome 7 and 17 also have high serum LDH levels (João et al., 2007). The authors of previous studies have also reported close correlation between chromosome abnormalities including str $17,+3$, and +18 and median survival period in NHL patients (Han et al., 2011). Analysis of the clinical data has revealed correlation between +3 and highly malignant NHL, mainly including diffused mixed type NHL. Those patients with str17 abnormalities cannot reach CR even after receiving systemic anti-tumor treatment, and have a shortened survival period. Researchers believe that the abnormal number of sex chromosomes in some NHL patients might be due to cell aging, because there is a more frequent occurrence of sex chromosome abnormalities in elderly patients. Unfortunately, in the present study, the number of sex chromosomes in the NHL patients was not evaluated, making it impossible to assess the relationship between age and sex chromosome abnormalities, which is the main limitation of the current study. The increased number of $+3,+5$, and +18 chromosome abnormalities and other clonal abnormalities (Swerdlow et al., 2008), are consistent with the results of this study.

Further logistic analysis revealed clinical stage, average LDH level, extra-node metastasis, median survival period, radio- and chemotherapy efficacy, and efficacy evaluation as independent risk factors for genetic alterations in Uighur NHL patients.

In conclusion, the occurrence of genetic changes including $\mathrm{t}(14: 18), 6 \mathrm{q} 21-25,+3,+7$, +18 , and $\operatorname{str} 17$ is correlated with clinical stage, average LDH level, extra-lymphatic metastasis, median survival time, and efficacy of radio- or chemotherapy. Those patients with advanced clinical stage, elevated LDH level, extra-node metastasis, shortened median survival period, and those who had received chemo- or radiotherapy, or experienced unfavorable treatment efficacy, were more susceptible to genetic change. Therefore, the analysis of patient genetics provides a novel approach to individualized treatment or optimization of treatment plans, and may provide novel treatment targets.

\section{Conflicts of interest}

The authors declare no conflict of interest.

Genetics and Molecular Research 15 (4): gmr15048960 


\section{ACKNOWLEDGMENTS}

Research supported by the Xinjiang Uygur Autonomous Region Xinjiang Science and Technology (mandatory) Project (\#201491185).

\section{REFERENCES}

Basso K, Saito M, Sumazin P, Margolin AA, et al. (2010). Integrated biochemical and computational approach identifies BCL6 direct target genes controlling multiple pathways in normal germinal center B cells. Blood 115: 975-984. http://dx.doi.org/10.1182/blood-2009-06-227017

Chen Y, Dave BJ, Zhu X, Chan WC, et al. (2013). Differences in the cytogenetic alteration profiles of diffuse large B-cell lymphoma among Chinese and American patients. Cancer Genet. 206: 183-190. http://dx.doi.org/10.1016/j. cancergen.2013.05.001

Ferlay J, Shin HR, Bray F, Forman D, et al. (2010). Estimates of worldwide burden of cancer in 2008: GLOBOCAN 2008. Int. J. Cancer 127: 2893-2917. http://dx.doi.org/10.1002/ijc.25516

Han YS, Xue YQ, Zhang J and Zhang HY (2011). Detection of BCL6 gene abnormalities in diffuse large B-cell lymphoma by fluorescence in situ hybridization on paraffin-embedded tissue section. Anhui Med. Pharmaceut. J. 15: 711-712.

Isaacson PG and Du MQ (2004). MALT lymphoma: from morphology to molecules. Nat. Rev. Cancer 4: 644-653.http:// dx.doi.org/10.1038/nrc1409

João C, Farinha P, da Silva MG, Martins C, et al. (2007). Cytogenetic abnormalities in MALT lymphomas and their precursor lesions from different organs. A fluorescence in situ hybridization (FISH) study. Histopathology 50: $217-$ 224.http://dx.doi.org/10.1111/j.1365-2559.2007.02580.x

Kahl B and Yang D (2008). Marginal zone lymphomas: management of nodal, splenic, and MALT NHL. Hematology (Am Soc Hematol Educ Program) 2008: 359-364. http://dx.doi.org/10.1182/asheducation-2008.1.359

Kim JM, Ko YH, Lee SS, Huh J, et al. (2011). WHO classification of malignant lymphomas in Korea: report of the Third Nationwide Study. Korean J. Pathol. 45: 254-260. http://dx.doi.org/10.4132/KoreanJPathol.2011.45.3.254

Klein U, Tu Y, Stolovitzky GA, Keller JL, et al. (2003). Transcriptional analysis of the B cell germinal center reaction. Proc. Natl. Acad. Sci. USA 100: 2639-2644. http://dx.doi.org/10.1073/pnas.0437996100

Kyle RA and Rajkumar SV (2006). Monoclonal gammopathy of undetermined significance. Br. J. Haematol. 134: 573589. http://dx.doi.org/10.1111/j.1365-2141.2006.06235.x

Luminari S, Cesaretti M, Rashid I, Mammi C, et al. (2007). Incidence, clinical characteristics and survival of malignant lymphomas: a population-based study from a cancer registry in northern Italy. Hematol. Oncol. 25: 189-197. http:// dx.doi.org $/ 10.1002 /$ hon. 826

Pervez S, Nasir MI, Moatter T, Ahsan A, et al. (2009). Characterization of genetic lesions in apoptosis-regulating and proliferation control genes in diffuse large B-cell non-Hodgkin's lymphoma. J. Cancer Res. Ther. 5: 254-262. http:// dx.doi.org/10.4103/0973-1482.59901

Roman E and Smith AG (2011). Epidemiology of lymphomas. Histopathology 58: 4-14. http://dx.doi.org/10.1111/j.13652559.2010.03696.x

Rossi D, Cerri M, Deambrogi C, Sozzi E, et al. (2009). The prognostic value of TP53 mutations in chronic lymphocytic leukemia is independent of Del17p13: implications for overall survival and chemorefractoriness. Clin. Cancer Res. 15: 995-1004.http://dx.doi.org/10.1158/1078-0432.CCR-08-1630

Siegel R, Ma J, Zou Z and Jemal A (2014). Cancer statistics, 2014. CA Cancer J. Clin. 64: 9-29. http://dx.doi.org/10.3322/ caac. 21208

Smedby KE, Hjalgrim H, Askling J, Chang ET, et al. (2006). Autoimmune and chronic inflammatory disorders and risk of non-Hodgkin lymphoma by subtype. J. Natl. Cancer Inst. 98: 51-60. http://dx.doi.org/10.1093/jnci/djj004

Stewart DA, Bahlis N and Mansoor A (2009). pY-STAT3 and p53 expression predict outcome for poor prognosis diffuse large B-cell lymphoma treated with high dose chemotherapy and autologous stem cell transplantation. Leuk. Lymphoma 50: 1276-1282. http://dx.doi.org/10.1080/10428190903015628

Streubel B, Lamprecht A, Dierlamm J, Cerroni L, et al. (2003). T(14;18)(q32;q21) involving IGH and MALT1 is a frequent chromosomal aberration in MALT lymphoma. Blood 101: 2335-2339.http://dx.doi.org/10.1182/blood-2002-09-2963

Swerdlow SH, Campo E, Harris NL, Jaffe ES, et al. (2008). WHO classification of tumours of haematopoietic and lymphoid tissues. 4th edn. IARC, Lyon.

Wang ZL, Yao YH, Sang L, Sun GX, et al. (2013). Research on correlation between immunophenotype and c-MYC rearrangement in diffuse large B cell lymphoma. Lab. Med. 28: 308-311.

Genetics and Molecular Research 15 (4): gmr15048960 
Yoon SO, Jeon YK, Paik JH, Kim WY, et al. (2008). MYC translocation and an increased copy number predict poor prognosis in adult diffuse large B-cell lymphoma (DLBCL), especially in germinal centre-like B cell (GCB) type. Histopathology 53: 205-217.http://dx.doi.org/10.1111/j.1365-2559.2008.03076.X

Zhang F, Yan LX, Lin SX, Ye ZY, et al. (2013). Immunophenotypic features and t(14;18) (q32;q21) translocation of Chinese follicular lymphomas helps to distinguish subgroups. Diagn. Pathol. 8: 154. http://dx.doi.org/10.1186/17461596-8-154

Zhang ZZ, Ni XZ and Shen YY (2010). Study of $t(14 ; 18)$ chromosomal translocation and bcl-2 gene amplification in gastrointestinal diffuse large B-cell lymphoma. J. Surg. Conc. Prac. 15: 143-147.

Genetics and Molecular Research 15 (4): gmr15048960 